\title{
Genetic relationships of Amaurobioides (Anyphaenidae) spiders from the southeastern coast of New Zealand
}

\author{
BRENT D. OPELL ${ }^{1}$, ANDREA M. BERGER, SOPHIA M. BOUS \& MICHAEL L. MANNING \\ Department of Biological Sciences, Virginia Polytechnic Institute and State University, Blacksburg, Virginia 24061, USA \\ ${ }^{1}$ Corresponding author.E-mail: bopell@vt.edu
}

\begin{abstract}
Members of the genus Amaurobioides construct silk retreats in rock crevices of the marine spray zone, a harsh and unusual habitat for spiders. This study expands the distribution records of three morphological species of Amaurobioides found on the eastern and southern coasts of New Zealand's South Island and uses mitochondrial DNA to examine their relationships and characterize their dispersal capabilities. Both 16S and ND1 sequences distinguish A. pletus found on the northeastern coast from a complex of two southern species comprised of A. maritimus from the mainland and $A$. picunus from Stewart Island. Neither 16S DNA nor ND1 protein separates these southern species. However, ND1 parsimony and likelihood analyses place 10 of 11 Stewart Island specimens in a clade of low support that nests deeply within $A$. maritimus. A nested haplotype analysis characterizes A. maritimus and A. picunus populations as having restricted gene flow/dispersal but with some long distance dispersal. Genetic distances between A. pletus and the A. maritimus-A. picunus complex indicate a Pliocene origin, whereas distances between A. maritimus and A. picunus suggest a Pleistocene divergence.
\end{abstract}

Key words: Amaurobioides maritimus, Amaurobioides picunus, Amaurobioides pletus, mitochondrial DNA, nested haplotype analysis, biogeography

\section{Introduction}

Spiders of the genus Amaurobioides Pickard-Cambridge (family Anyphaenidae) live in the marine spray zone, where they construct silk retreats in rock crevices at or slightly below mean high tide level (Figs. 1; Forster 1970; Forster \& Forster 1999; BDO personal observations). In New Zealand, these spiders are typically found on rock outcrops, although large boulders also provide suitable habitat (BDO unpublished observations). Consequently, soft sandstone that erodes easily or beaches of sand or gravel act as barriers to their dispersal. Amaurobioides are known from only a few sites, even along the eastern and southern coasts of New Zealand's South Island (SI), where collecting has been most extensive. Before the current study, A. pletus Forster was known only from Akaroa (Fig. 2), A. maritimus Cambridge only from Brighton, Black Head, and two sites a few km north of these, and A. picunus Forster only from Halfmoon Bay and adjacent Horseshoe Bay on the northeast coast of Stewart Island.

There are no conspicuous ecological differences among Amaurobioides species (BDO unpublished observations), although A. maritimus and A. picunus adults are larger than those of A. pletus (Forster 1970; BDO unpublished observations). Nothing is known about the mode or frequency of dispersal in Amaurobioides. After depositing an egg sac within her retreat, a female seals the retreat opening with silk and remains inside until spiderlings emerge from the sac (Forster 1970; BDO unpublished observations). Spiderlings live in the maternal retreat with the female for an undetermined period of time after they emerge from an egg sac (BDO 
personal observations), suggesting that early dispersal, where ballooning might be expected to be more common, may be limited. The small number of mature males reported by Forster (1970), present in the Otago Museum, and collected by BDO may indicate that males spend more time away from their retreats or travel longer distances than females and, consequently, suffer higher mortality.

New Zealand's biogeography bears the imprint of geological events during the Oligocene, Pliocene, and Pleistocene that created physical barriers to the dispersal of plants and animals. During the Oligocene (32 Ma) erosion and rising sea levels restricted landmass to small areas in the south of the SI and the north central region of the North Island (NI) (Suggate 1978; Cooper \& Cooper 1995; Trewick \& Morgan-Richards 2005). Land area expanded during the Miocene and from 15-10 Ma formed a single slender island, which was again divided during the early Pliocene (5 Ma) into islands roughly the size of the present NI and SI (Suggate 1978; Morgan-Richards et al. 2000; Trewick \& Wallis 2001). During the Pleistocene (1.8 Ma-14,000), sea level dropped, connecting NI, SI, and Stewart Islands (Fleming 1979; Thornton 1985). On the SI, extensive glaciation drastically reduced the habitable area and altered climate and vegetation, impacting the diversity and distribution of many terrestrial invertebrates (Trewick 2000; Trewick \& Wallis 2001; Neiman \& Lively 2004; Trewick \& Morgan-Richards 2005).

The objectives of this study were to: 1 . More fully characterize the distributions of A. pletus and A, maritimus by collecting specimens from unsampled localities, 2. Characterize differences among A. pletus, A, maritimus, and A. picunus, 3. Infer relationships among these species, and 4. Estimate their times of divergence. Forster (1970) distinguished A, pletus, A. maritimus, and A. picunus by genitalic differences, which suggest that the latter two species are closely related. However, the small differences in these morphological features, the small number of specimens available for study, and the variability of these features suggest that a re-examination of these species is warranted (R. Forster, conversation with BDO, January, 2000). As demonstrated by studies cited above, molecular data are well suited to these tasks. In this study we use two mitochondrial genes, 16S and NADH dehydrogenase subunit ND1, both of which have been employed successfully to reconstruct the phylogenies of spider populations and species (Hedin 1997a, b; Gillespie 1999; Hedin \& Maddison 2001; Bond et al. 2001; Masta \& Maddison 2002; Maddison \& Hedin 2003; Vink \& Paterson 2003; Griffiths et al. 2005; Garb \& Gillespie 2006).

\section{Materials and methods}

This study is based on specimens collected by BDO from 16 localities (Table 1, Fig. 2) under permits issued by the New Zealand Department of Conservation. Most were collected during January and February 2000, but those from Taylor's Mistake, Camp Bay, and Tumbledown Bay were collected during January 2004. With one exception, each specimen was prodded from its retreat with a small wire, collected in a glass vial, and preserved in 95\% ethanol. One specimen from Stewart Island (the single specimen that shared ND1 haplotype $\mathrm{N} 9$, with mainland sites) was found dead on the shore in a partially dried condition. All specimens will be deposited in New Zealand's Otago and Canterbury Museums.

DNA was extracted from two legs of each specimen using a Puregene DNA isolation kit from Gentra Systems, Inc. We used the PCR primers and thermocycler parameters of Hedin (1997a, b) to amplify a $425 \mathrm{bp}$ portion of the $16 \mathrm{~S}$ mitochondrial gene and the entire 429 bp ND1 subunit of the mitochondrial NADH dehydrogenase. Prior to sequencing, we prepared most PCR products by electrophoresis on agarose gels, staining bands with EtBr, excising bands, and cleaning them with a QIAquick ${ }^{\circledR}$ gel extraction kit. The PCR products of specimens collected at Taylor's Mistake, Camp Bay, and Tumbledown Bay were cleaned with a QIAquick® PCR purification kit. We then performed cycle sequencing with Biosystems' Big Dye Terminator ${ }^{\mathrm{TM}}$ chemistry, ran products on agarose gels, stained them with $\mathrm{EtBr}$, and excised bands. After cleaning this labeled product with a Qiagene Gel Kit, we read DNA sequences with an Applied Biosystems 3100 genetic 


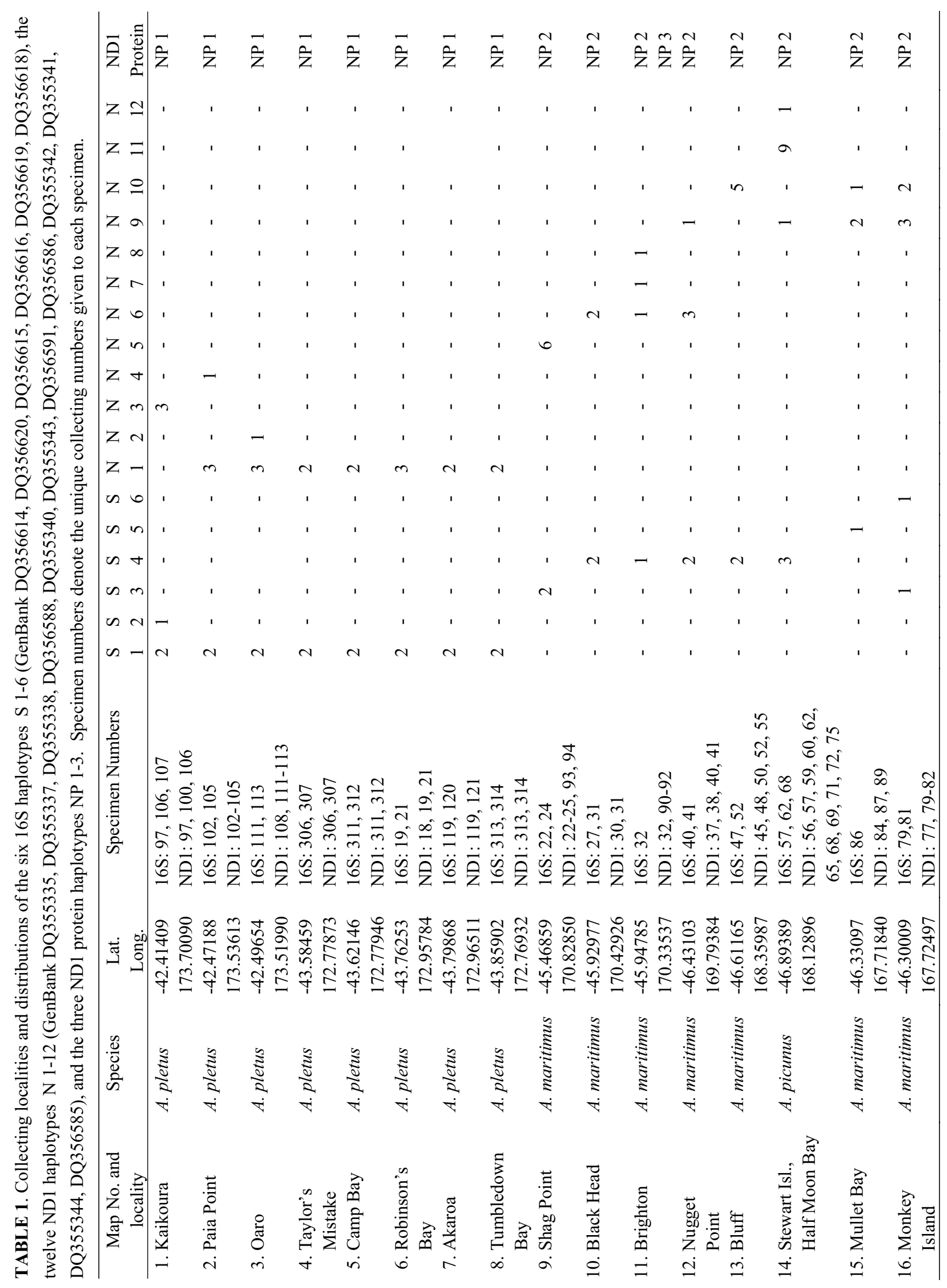


analyzer, and edited Electropherograms with the EditView program. We aligned the edited sequences with Clustal V (Higgins et al. 1996), as implemented by DNA Star, with parameters set as follows: multiple alignment gap penalty 10, gap length penalty 10; pairwise alignment ktuple 2, gap penalty 5 , window 4, diagnols 4 . No indels were required to align either $16 \mathrm{~S}$ or ND1 sequences.

Maximum parsimony (MP) analyses (settings: collapse branches if maximum length is zero, ACCTRAN) were performed with Paup* 4.0b10 (Swofford 1998). We used an exhaustive search for the analysis of 16S DNA and a branch and bound search (options: compute via stepwise, addition sequence furthest) for ND1 DNA. Bootstrap settings were: 1000 replicates, full heuristic, retain groups with frequency $>50 \%$, addition sequence simple, starting tree generated by stepwise addition, for multiple swapping trees swap on best only, TBR swapping.

We used MODELTEST 3.7 (Posada \& Crandall 1998) to determine the appropriate model and parameters (Posada \& Crandall 2001; Posada \& Buckley 2004) to use in maximum likelihood (ML) estimations run with PAUP 4.0b10. Maximum likelihood trees were obtained by heuristic searches performed with TBR branch swapping from starting trees obtained by stepwise addition and 200 random addition sequence replicates. Bootstrap values are based on 100 replicates.
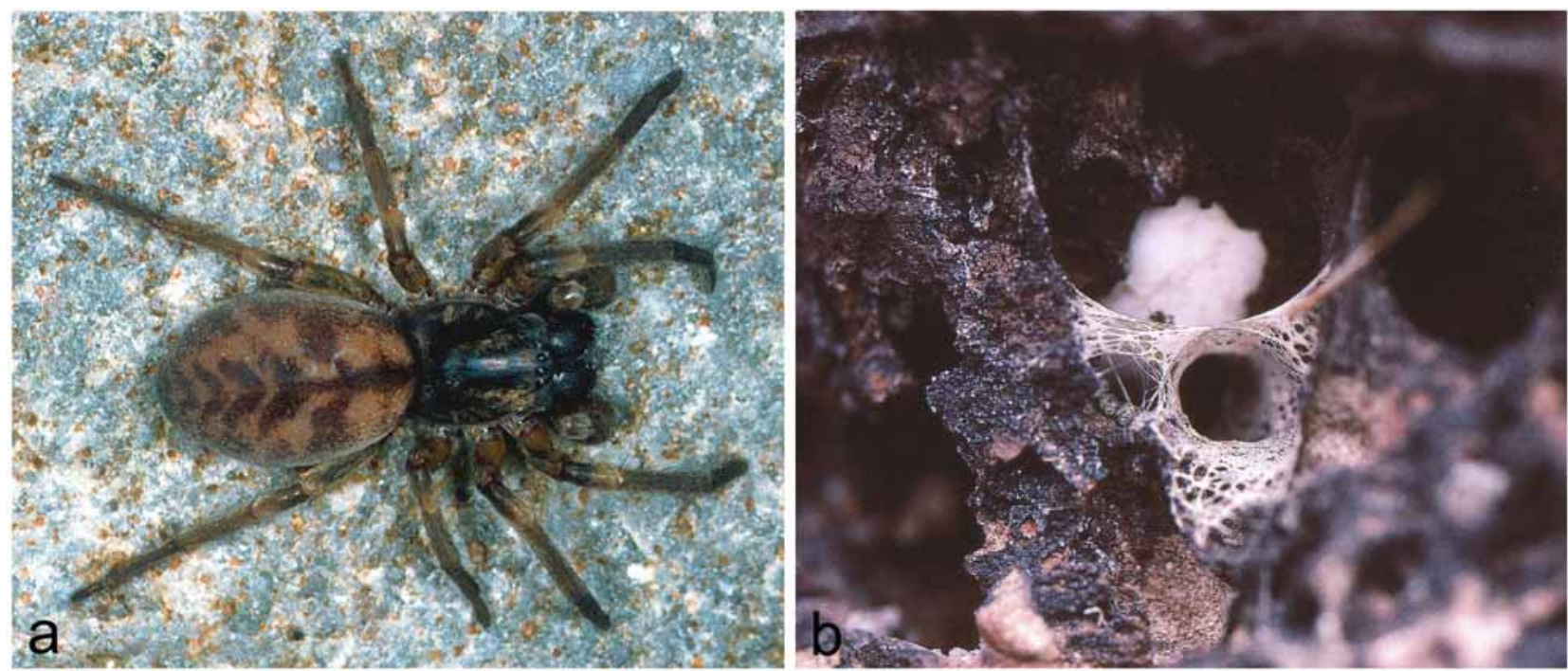

FIGURE 1. a. An adult female A. maritimus from Black Head. b. A silk retreat of A. pletus from Akaroa.

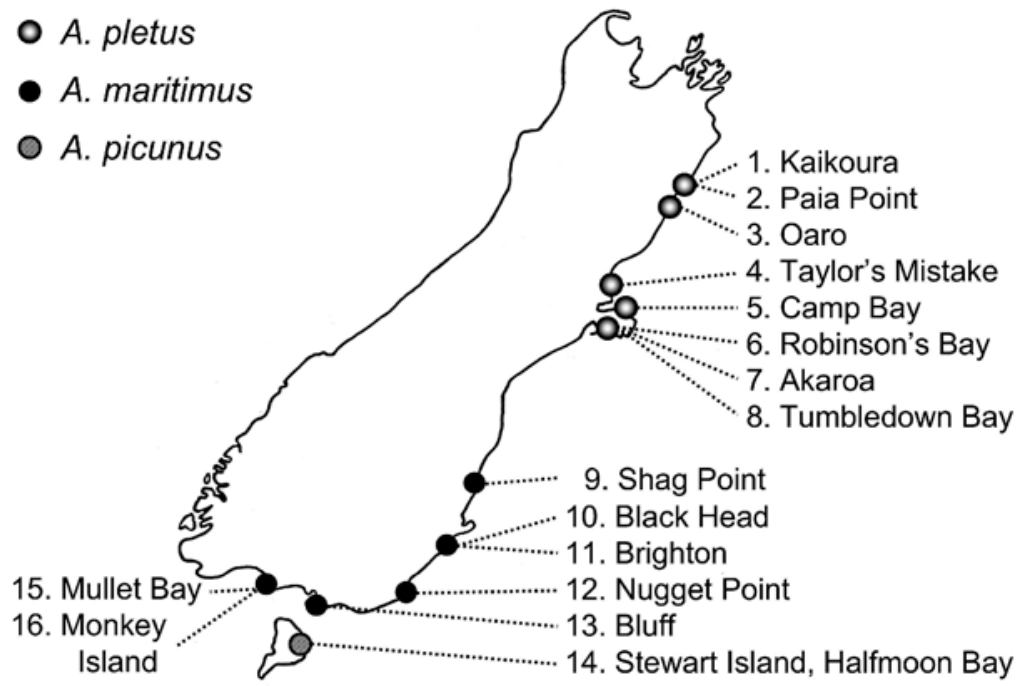

FIGURE 2. Distribution of the localities from which specimens included in this study were collected. Numbers refer to the localities identified in Table 1. 
Data were exported from PAUP for use in a Templeton, Crandall, Sing analyses (statistical parsimony analysis; Crandall et al. 1994; Templeton 1998; Templeton et al. 1992) implemented with the TCS program (Clement et al. 2000). As there were no indels in either $16 \mathrm{~S}$ or ND1 DNA, the gaps $=5^{\text {th }}$ state or gaps $=$ missing options produced identical networks. A 95\% confidence limit was used for the inclusion of haplotypes in a network.

We performed a nested clade haplotype analysis (Templeton et al. 1987, 1995; Crandall 1994, 1996) using the GeoDis 2.4 program and its November 2005 inference key (Posada \& Templeton 1999-2005). We restricted this analysis to the ND1 haplotypes of A. maritimus and A. picunus, as they were included in the same network and provided a sufficiently complex network for a meaningful analysis. For this analysis, we used shoreline distances between localities measured with Image J (Image J 2006) from an enlarged digital map of the South Island. The distances from Half Moon Bay, Stewart Island to all localities pass through Bluff, whose straight-line distance from Half Moon Bay is $37 \mathrm{~km}$.

\section{Results}

Six 16S haplotypes were represented among 32 specimens and 12 ND1 haplotypes were represented among 61 specimens (Figs. 3, 4). Tables 2 and 3 present the pairwise Kimura 2-parameter (K2P; Kimura 1980) and uncorrected $p$ distances between these haplotypes. GenBank assigned a 132 amino acid sequence to each ND1 DNA haplotype. Only three proteins were represented among these haplotypes, one for A. pletus, one for A. maritimus and A. picunus, and one for a single A. maritimus specimen from Brighton (Fig. 2).
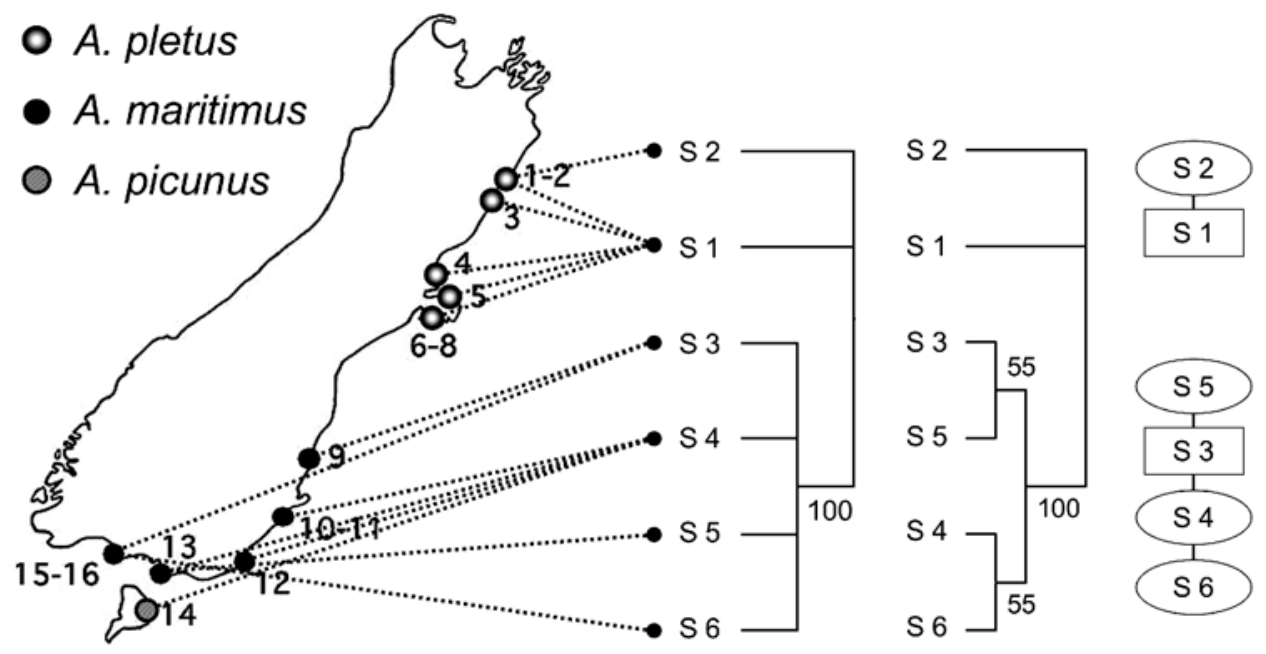

FIGURE 3. Maximum parsimony cladogram (left), maximum likelihood tree (center), and TCS network of 425 base pairs ( 9 of them parsimony-informative) of six 16S DNA haplotypes. The cladogram is a strict consensus of three trees, each with $\mathrm{CI}=0.93, \mathrm{RI}=0.90$ (rescaled $=0.84$ ). Parsimony bootstrap values are based on 1000 replicates and likelihood bootstrap values on 100 replicates.

MODELTEST selected two Tamura-Nei models (Tamura \& Nei 1993): TRN+1 for 16S and TRN for ND1. The parameters for $16 \mathrm{~S}$ were: base frequencies: $\mathrm{A}=0.4431, \mathrm{C}=0.1067, \mathrm{G}=0.1086, \mathrm{~T}=0.3416$; Rate matrix: $\mathrm{A}-\mathrm{G}=1.8741, \mathrm{C}-\mathrm{T}=39.7716$, all others $=1.0000$; proportion of invariable sites $=0.8837$, variable sites $(\mathrm{G})$; equal rates for all sites. The parameters for ND1 were: base frequencies: $A=0.4057, C=0.1445, G$ $=0.0803, \mathrm{~T}=0.3695$; rate matrix: $\mathrm{A}-\mathrm{G}=2.2065, \mathrm{C}-\mathrm{T}=27.3047$, all others $=1.0000$; proportion of invariable sites $=0$, variable sites $(\mathrm{G})$, equal rates for all sites.

The unrooted 16S and ND1 MP and ML trees (Figs. 3, 4) each united the two southern species, A. maritimus and A. picunus, in a clade with $100 \%$ bootstrap support. In the $16 \mathrm{~S}$ trees, Stewart Island specimens shared 
the most common haplotype (S4) with four other mainland sites. Although the 16S ML tree further subdivides the southern clade, these two subclades have equivocal support. Ten of the 11 specimens from Stewart Island had ND1 haplotypes N11 and N12, which are restricted to the island and form a clade with minimal bootstrap support. The eleventh specimen (the individual found dead) shared haplotype N9 with three mainland localities. TCS networks show nearly identical patterns to those described above, each retaining only A. maritimus and A. picunus within the same network at a 95\% confidence interval. The two A. pletus $16 \mathrm{~S}$ haplotypes (S1$\mathrm{S} 2$ ) are separated from the four A. maritimus-A. picunus haplotypes (S3-S6) by a mean K2P of 2.397\% \pm 0.065 standard error (SE). The two unique A. picunus ND1 haplotypes (N11-N12) are separated from the two A. maritimus haplotypes in their subclade (N6-N7) by a mean K2P of $0.468 \% \pm 0.096 \mathrm{SE}$. The four A. pletus ND1 haplotypes (N1-N4) are separated from the eight $A$. maritimusi-A. picunus haplotypes (N5-N12) by a mean K2P of $9.263 \pm 0.092$ SE. The two A. maritimus ND1 protein haplotypes differed by a single amino acid (uncorrected $p=0.00758$ ) and the two widely distributed NP1 and NP2 haplotypes differed by 6 amino acids (uncorrected $p=0.04545$ ).
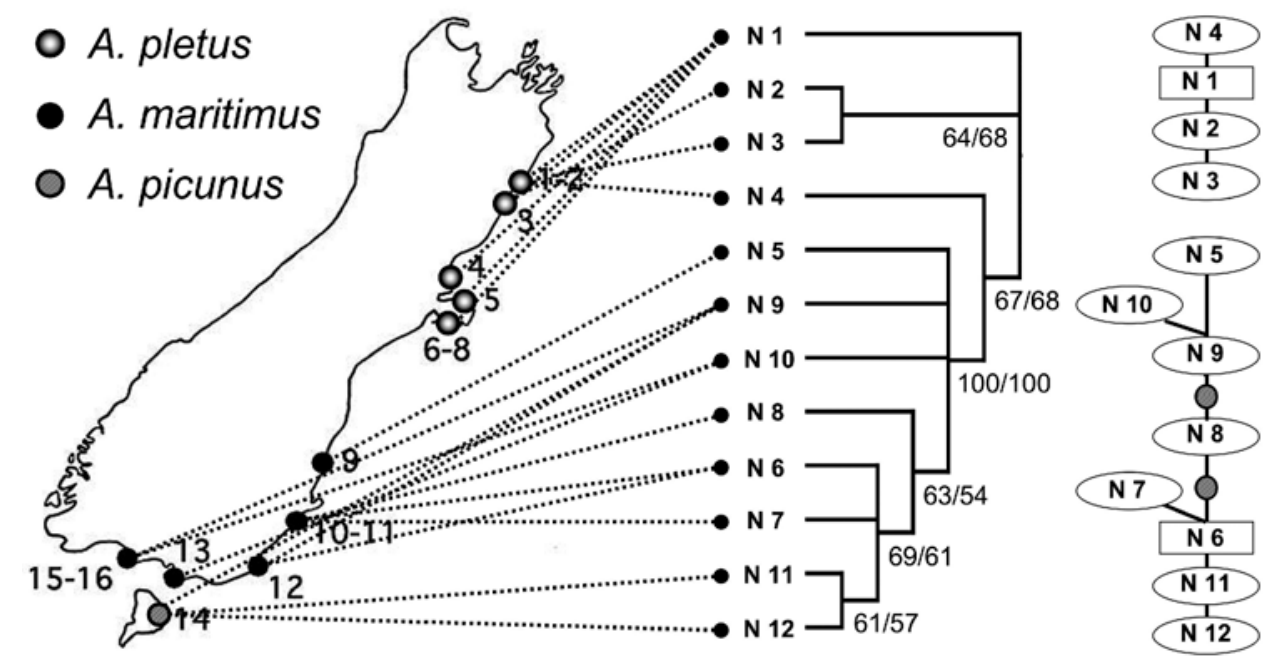

FIGURE 4. Maximum parsimony cladogram and identical maximum likelihood tree (left) and TCS network of 429 base pairs (39 of them parsimony-informative) of 12 ND1 DNA haplotypes. The cladogram is a strict consensus of two trees, each with $\mathrm{CI}=0.96, \mathrm{RI}=0.98$ (rescaled $=0.94$ ). Parsimony bootstrap values (left) are based on 1000 replicates and likelihood bootstrap values (right) on 100 replicates. Small, shaded circles in the TCS network represent inferred, missing haplotypes.

TABLE 2. Pairwise distances between $16 \mathrm{~S}$ haplotypes. Kimura 2-parameter values are given in the upper triangle and uncorrected $p$ values in the lower triangle.

\begin{tabular}{lllllll}
\hline & S1 & S2 & S3 & S4 & S5 & S6 \\
\hline S1 & & 0.00236 & 0.02397 & 0.02397 & 0.02642 & 0.02642 \\
S2 & 0.00235 & & 0.02152 & 0.02152 & 0.02397 & 0.02397 \\
S3 & 0.02353 & 0.02118 & & 0.00236 & 0.00236 & 0.00473 \\
S4 & 0.02353 & 0.02118 & 0.00235 & & 0.00473 & 0.00473 \\
S5 & 0.02588 & 0.02353 & 0.00235 & 0.00471 & & 0.00711 \\
S6 & 0.02588 & 0.02353 & 0.00471 & 0.00235 & 0.00706 & \\
\hline
\end{tabular}

The nested cladogram shown in Figure 5 differs slightly from the ND1 network of Figure 4. Clade 1-1 is comprised of three haplotypes that are represented at a total of 8 localities and clade 1-2 is comprised of five haplotypes that are represented at a total of five localities. Haplotypes N8, N11, and N12 of clade 1-2 are each 
present at only a single locality and haplotypes N11 and N12 are both present only at locality 14 . This makes it inappropriate to have a nested clade comprised of haplotype N8 alone, haplotype N11 alone, or haplotype N12 alone. Therefore, we combined haplotype N8 with haplotype N6 to form a single clade within nested clade 1-2 and haplotypes N11 and N12 to form another clade within nested clade 1-2. The permutational contingency tests for clades 1-1 and 1-2 and for the total cladogram each had a $P$ value of 0.0000 and each moved through the inference key couplets as follows: 1, 2, 3, 5, and 6: "insufficient genetic resolution to discriminate between range expansion/colonization and restricted dispersal/gene flow." Couplet 7 then concluded that the ND1 nested cladogram was explained by "restricted gene flow/dispersal but with some long distance dispersal".

TABLE 3. Pairwise distances between ND1 haplotypes. Kimura 2-parameter values are given in the upper triangle and uncorrected $p$ values in the lower triangle.

\begin{tabular}{lllllllllllll}
\hline & $\mathrm{N} 1$ & $\mathrm{~N} 2$ & $\mathrm{~N} 3$ & $\mathrm{~N} 4$ & $\mathrm{~N} 5$ & $\mathrm{~N} 6$ & $\mathrm{~N} 7$ & $\mathrm{~N} 8$ & $\mathrm{~N} 9$ & $\mathrm{~N} 10$ & $\mathrm{~N} 11$ & $\mathrm{~N} 12$ \\
\hline $\mathrm{N} 1$ & & 0.00234 & 0.00468 & 0.00234 & 0.08787 & 0.09338 & 0.09616 & 0.09062 & 0.08514 & 0.08787 & 0.09616 & 0.09357 \\
$\mathrm{~N} 2$ & 0.00233 & & 0.00234 & 0.00468 & 0.09062 & 0.09616 & 0.09895 & 0.09338 & 0.08787 & 0.09062 & 0.09895 & 0.09636 \\
$\mathrm{~N} 3$ & 0.00466 & 0.00233 & & 0.00704 & 0.09062 & 0.09895 & 0.10176 & 0.09616 & 0.09062 & 0.09338 & 0.10176 & 0.09916 \\
$\mathrm{~N} 4$ & 0.00233 & 0.00466 & 0.00699 & & 0.08514 & 0.09062 & 0.09338 & 0.08787 & 0.08242 & 0.08514 & 0.09338 & 0.09080 \\
$\mathrm{~N} 5$ & 0.08159 & 0.08392 & 0.08625 & 0.07925 & & 0.01179 & 0.01419 & 0.00704 & 0.00234 & 0.00468 & 0.01419 & 0.01655 \\
$\mathrm{~N} 6$ & 0.08625 & 0.08858 & 0.09091 & 0.08392 & 0.01166 & & 0.00234 & 0.00468 & 0.00941 & 0.00704 & 0.00234 & 0.00468 \\
N7 & 0.08858 & 0.09091 & 0.09324 & 0.08625 & 0.01399 & 0.00233 & & 0.00704 & 0.01179 & 0.00941 & 0.00468 & 0.00703 \\
N8 & 0.08392 & 0.08625 & 0.08858 & 0.08159 & 0.00699 & 0.00466 & 0.00699 & & 0.01179 & 0.00704 & 0.00704 & 0.00939 \\
N9 & 0.07925 & 0.08159 & 0.08392 & 0.07692 & 0.00233 & 0.00932 & 0.01166 & 0.00466 & & 0.00234 & 0.01179 & 0.01416 \\
N10 & 0.08159 & 0.08392 & 0.08625 & 0.07925 & 0.00466 & 0.00699 & 0.00932 & 0.00699 & 0.00233 & & 0.00941 & 0.01177 \\
N11 & 0.08858 & 0.09091 & 0.09324 & 0.08625 & 0.01399 & 0.00233 & 0.00466 & 0.00699 & 0.01166 & 0.00932 & & 0.00234 \\
N12 & 0.08625 & 0.08858 & 0.09091 & 0.08392 & 0.01632 & 0.00466 & 0.00699 & 0.00932 & 0.01399 & 0.01166 & 0.00233 & \\
\hline
\end{tabular}

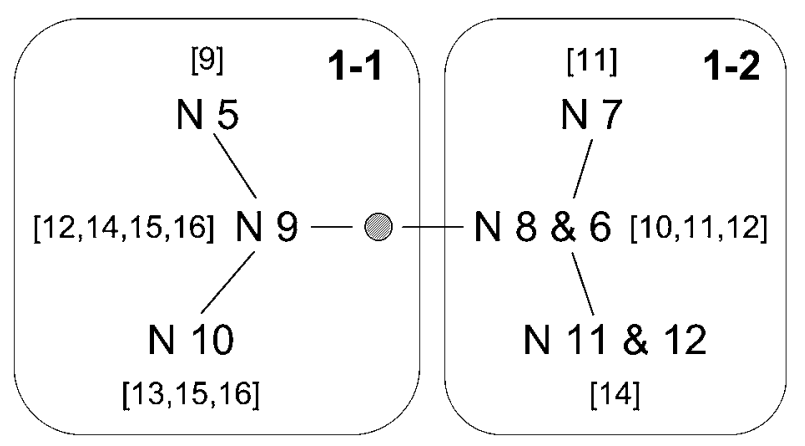

FIGURE 5. ND1 nested cladogram based on the TCS diagram shown in Fig. 4, showing relationships between haplotypes N1 -12 and the localities at which these haplotypes are found as smaller numbers in brackets.

\section{Discussion}

Specimens collected during the course of this study extend the known ranges of A. pletus and A. maritimus. The range of A. pletus extends from the previously known Kiakoura locality southward to Akaroa and Tumbledown bay on the south shore of Bank's Peninsula (Fig. 2). A long stretch of coast that appears to be comprised of predominately sand and gravel beaches separates Bank's Peninsula from the rocky shores of Shag Point, the northern-most record of A. maritimus. The range of A. maritimus extends along the remainder of the eastern and southern coast to Monkey Island, where gravel beaches extend westward to the end of road access 
to the coast and into the Fiordlands beyond.

Both 16S and ND1 genes are useful in recovering relationships among Amaurobioides. As shown in other studies (e.g., Hedin 1997b; Hedin \& Maddison 2001), ND1 evolves more rapidly than 16S and, therefore, provides more resolution. The mean $\mathrm{K} 2 \mathrm{P}$ distance of $9.263 \%$ that separates the ND1 sequences of $A$. pletus from the A. maritimus-A. pletus complex attests to the distinctness of these species. This distance is similar to or greater than that observed among New Zealand onychophorans and insects (Trewick 2000; Trewick \& Wallis 2001), about twice that observed for the oldest clades of Hawaiian tetragnathid spiders (Gillispie 1999), and almost ten times the greatest distance that separates populations of New Zealand's two widow spider species (Griffiths et al. 2005). A rate of 2\% (e.g., Brown et al. 1979; DeSalle et al. 1987; Juan, et al. 1995; Gillespie 1999; Trewick \& Morgan-Richards 2005) or 2.3\% (e.g., Brower 1994; Trewick \& Wallis 2001; Garb \& Gillespie 2006) mitochondrial DNA sequence divergence per million years is often used to estimate the coalescence time of clades. This indicates that A. pletus and the A. maritimus-A. pletus complex diverged 4.0-4.6 Ma.

This date suggests an early to middle Pliocene origin for these species through geographical isolation on the NI and SI, respectively. When these islands were joined during the Pleistocene, A. pletus probably invaded the SI, migrating southward as far as Bank's Peninsula. The $200 \mathrm{~km}$ of shore that separates A. pletus and A. maritimus corresponds roughly to the SI's central or Canterbury region of low endemicity. This region is often referred to as the "beech-gap" because there is disjunction in the distribution of many species, including Nothofagus species, in this region (Burrows 1965; Heads 1998; Trewick \& Wallis 2001). During the Pleistocene, glaciers from the Southern Alps extended nearly halfway across this narrow portion of the SI, producing a large outwash aggregate field that extended to the coast (Fleming 1979; Trewick \& Wallis 2001). Elevated by Miocene volcanism (Thornton, 1985), Bank's Peninsula (Fig. 2, localities 5-8) was probably less affected by these events and may have served as a refuge for Amaurobioides. Although animal and plant species have colonized this central zone in the 14,000 years since the glaciers receded, it appears to remain a formidable barrier to the dispersal of Amaurobioides.

The species status of A. picunus is not well supported by our analysis. Neither 16S DNA nor ND1 proteins distinguished a Stewart Island clade. Although, 10 of the 11 specimens from Stewart Island have the unique N11 and N12 haplotypes, these haplotypes form a clade that nests deeply within A. maritimus and has low bootstrap support. If Stewart Island haplotypes represent a distinct lineage, the mean K2P distance of $0.468 \%$ that separates it from the most closely related mainland haplotpes (N6 \& N7) indicates a separation of 0.2$0.23 \mathrm{Ma}$. Like Stewart Island populations of the freshwater fish Galaxias gollumoides McDowall \& Chadderton that share haplotypes with populations in Southland rivers (Walters et al. 2001), Stewart Island Amaurobioides are closely allied with mainland populations. This contrasts with the $7 \%$ sequence divergence that separates the endemic Stewart Island giant weta, Deinacrida carinata Salmon, found in lowland vegetation from the more wide-spread mainland $D$. connectens Ander, which lives under rocks in the alpine zone (Trewick \& Morgan-Richards 2005).

Although Amaurobioides spiders are restricted to the marine shore, their distribution appears to conform to biogeogrpahic regions established for terrestrial animals and plants. These comprise a southern OtagoSouthland region, a central Canterbury region of low endemism, a northeastern Marlborough region, and a northwestern Nelson region. (Trewick \& Wallis 2001; Neiman \& Lively 2004). Specimens collected more recently from the northern and western coasts of the SI and from the NI will allow us to determine if A. pletus is confined to the Marlborough region or if it extends into the Nelson region. This material will also allow us to more fully characterize the distribution and diversity of New Zealand Amaurobioides and to delineate species using molecular and morphological characters. 


\section{Acknowledgments}

Collecting on the northern and southern shores of Banks Peninsula was supported by a grant from the National Geographic Society. Simon Pollard, Lyn Forster, Shirley McQueen, Ilana Batchelor, and Chris Green helped arrange collecting and export permits that were issued by New Zealand's Department of Conservation. Simon Pollard served as an in-country collaborator on the National Geographic Society research grant, organized a collecting trip to Tumbledown Bay, and helped collect spiders there. I am grateful to the late Raymond Forster for discussions and encouragement during this study. The comments of an anonymous reviewer greatly improved the manuscript.

\section{References}

Bond, J.E., Hedin, M.C., Ramirez, M.G., \& Opell, B.D. (2001) MtDNA phylogeography of the Californian costal dune endemic trapdoor spider Aptostichus simus: deep molecular divergence in the absence of morphological and ecological change. Molecular Ecology 10, 899-910.

Brower, A.V.A. (1994) Rapid morphological radiation and convergence among races of the butterfly Heliconius erato inferred from patterns of mitochondrial DNA evolution. Proceedings of the National Academy of Science, U.S.A., 91, 6491-6495.

Brown, W.M., George jr, M., \& Wilson, A.C. (1979) Rapid evolution of animal mitochondrial DNA. Proceedings of the National Academy of Science, U.S.A., 76, 1967-1971.

Burrows, C.J. (1965) Some discontinuous distributions of plants within New Zealand and their ecological significance. Part II. Disjunctions between Otago-Southland and Nelson-Marlborough and related distribution patterns. Tuatara, 13, 9-29.

Clement, M.D., Posada, D., \& Crandall, K.A. (2000) TCS: a computer program to estimate gene genealogies. Molecular Ecology, 9, 1657-1660.

Cooper, A., \& Cooper, R.A. (1995) The Oligocene bottleneck and New Zealand biota: genetic record of a past environmental crisis. Proceedings of the Royal Society, London B, 261, 293-302.

Crandall, K.A. (1994) Intraspecific cladogram estimation: accuracy at higher levels of divergence. Systematic Biology, $43,222-235$.

Crandall, K.A., Templeton, A.R., \& Sing, C.F. (1994) Intraspecific phylogenetics: problems and solutions. In: Scotland, R.W., Siebert, D.J. \& Williams DM (Ed.), Models in Phylogeny Reconstruction. Clarendon Press, Oxford, pp. 273298.

Crandall, K.A. (1996) Multiple interespecies transmissions of human and simian T-cell leukemia/lymphoma virus type I sequences. Molecular Biology and Evolution, 13, 115-131.

DeSalle, R, Freedman, T., Prager, E.M., \& Wilson, A.C. (1987) Tempo and mode of sequence evolution in mitochondrial DNA of Hawaiian Drosophila. Journal of Molecular Evolution, 26, 157-164.

Fleming, C. (1979) Geological history of New Zealand and its Life. Auckland University Press, Auckland, 141 pp.

Forster, R.R. (1970) The spiders of New Zealand, part III. Otago Museum Bulletin, 3, 1-184.

Forster, R.R. \& Forster, L. (1999) Spiders of New Zealand and Their Worldwide Kin. University of Otago Press, Dunedin, 270 pp.

Garb, J.E. \& Gillesspie, R.G. (2006) Island hopping across the central Pacific: mitochondrial DNA detects sequential colonization of the Austral Islands by crab spiders (Araneae: Thomisidae). Journal of Biogeography, 33, 201-220.

Gillespie, R.G. (1999) Comparison of rates of speciation in web-building and non-web building groups within a Hawaiian spider radiation. Journal of Arachnology, 27, 79-85.

Griffiths, J.W., Paterson, A.M., \& Vink, C.J. (2005) Molecular insights into the biogeography and species status of New Zealand's endemic Latrodectus spider species; L. katipo and L. atritus (Araneae, Theridiidae). Journal of Arachnology, 33, 776-784.

Heads, M. (1998) Biogeographic disjunction along the Alpine Fault, New Zealand. Biological Journal of the Linnean Society, 63, 161-176.

Hedin, M.C. (1997a) Molecular phylogenetics at the population/species interface in cave spiders of the Southern Appalachians (Araneae: Nesticidae: Nesticus). Molecular Biology and Evolution, 14, 309-324.

Hedin, M.C. (1997b) Speciational history in a diverse clade of habitat - specialized spiders (Araneae: Nesticidae: Nesticus): Inferences from geographic-based sampling. Evolution, 5, 1929-1945.

Hedin, M.C. \& Maddison, W.P. (2001) A combined molecular approach to phylogeny of the jumping spider subfamily Dendrophantinae (Araneae: Salticidae). Molecular Phylogeny and Evolution, 18, 386-403. 
Higgins, D.G., Bleasby, A.J. \& Fuchs, R. (1996) Clustal V: Improved software for multiple sequence alignment. Comparative and Applied Bioscience, 8, 189-191.

Image J (2006) http://www.uhnresearch.ca/facilities/wcif/imagej/.

Juan, C., Oromi, P., \& Hewitt, G.M. (1995) Mitochondrial DNa phylogeny and sequential colonization of Canary Islands by darkling beetles of the genus Pimelia (Tenebrionidae). Proceedings of the Royal Society, London, Series B, 261, 173-180.

Kimura, M. (1980) A simple method for estimating evolutionary rate of base substitutions through comparative studies of nucleotide sequences. Journal of Molecular Evolution, 16, 111-120.

Maddison, W. \& Hedin, M. (2003) Phylogeny of Habronattus jumping siders (Araneae: Salticidae), with consideration of genitalic and courtship evolution. Systematic Entomology, 28, 1-21.

Masta, S.E. \& Maddison, W.P. (2002) Sexual selection driving diversification in jumping spiders. Proceedings of the National Academy of Science, USA, 99, 4442-4447.

Morgan-Richards, M., Trewick, S.A., \& Wallis, G.P. (2000) Chromosome races with Pliocene origins: evidence from mtDNA. Heredity, 86, 303-312.

Neiman, M. \& Lively, C.M. (2004) Pleistocene glaciation is implicated in the phylogeographical structure of Potamopyrgus antipodarum, a New Zealand snail. Molecular Ecology, 13, 2085-3098.

Posada, D. \& Buckley T.R. (2004) Model selection and model averaging in phylogenetics: advantages of the AIC and Bayesian approaches over likelihood ratio tests. Systematic Biology, 53, 793-808.

Posada, D. \& Crandall, K.A. (1998) MODELTEST: testing the model of DNA substitution. Bioinformatics 14, 817-818.

Posada, D. \& Crandall, K. A. (2001) Selecting the best-fit model of nucleotide substitution. Systematic Biology, 50, 580601.

Posada, D. \& Templeton, A.R. (1999-2005) GEODIS 2.5 documentation. Provo, Utah. Available from: http:// darwin.uvigo.es (2 March 2006).

Suggate, R.P., ed. (1978) The Geology of New Zealand, vol. 2. E. C. Keating, Government Printer, Wellington, pp. 345820.

Swofford, D.L. (1998) PAUP*. Phylogenetic analysis using parsimony (*and other methods), vers 4. Sinauer Associates, Sunderland.

Tamura, K. Nei, M. (1993) Estimation of the number of nucleotide substitutions in the control region of mitochondrial DNA in humans and chimpanzees. Molecular Biology and Evolution, 10, 512-526.

Templeton, A.R. (1998) Nested clade analysis of phylogeographic data: testing hypotheses about gene flow and population history. Molecular Ecology, 7, 381-397.

Templeton, A.R., Boerwinkle, E. \& Sing, C.F. (1987) A cladistic analysis of phenotypic associations with haplotypes inferred from restriction endonuclease mapping and DNA sequence data. I. Basic theory and an analysis of alcohol dehydrogenase activity in Drosophila. Genetics, 117, 343-351.

Templeton, A.R., Crandall, K.A. \& Sing, C.F. (1992) A cladistic analysis of phenotypic associations with haplotypes inferred from restriction endonuclease mapping and DNA sequence data. III. Cladogram estimation. Genetics, 132, 619-633.

Templeton, A.R., Routman, E. \& Phillips, C.A. (1995) Separating population structure from population history: A cladistic analysis of the geographical distribution of mitochondrial DNA haplotypes in the tiger salamander, Ambystoma tigrinum. Genetics, 140, 767-782.

Thornton, J. (1985) New Zealand Geology. Reed Books, Auckland, 226 pp.

Trewick, S.A. (2000). Molecular evidence for dispersal rather than vicariance as the origin of flightless insect species on the Chatham Islands, New Zealand. Journal of Biogeography, 27, 1189-1200.

Trewick, S.A., Morgan-Richards, M. (2005). After the deluge: mitochondrial DNA indicates Miocene radition and Pliocene adaptation of tree and giant weta (Orthoptera: Anostostomatidae). Journal of Biogeography, 32, $295-309$.

Trewick, S.A. \& Wallis, G.P. (2001) Bridging the "beech-gap": New Zealand invertebrate phylogeography implicates Pleistocene glaciation and Pliocene isolation. Evolution, 55: 2170-2180.

Vink, C.J. \& Paterson, A.M. (2003) Combined molecular and morphological phylogenetic analyses of the New Zealand wolf spider genus Anoteropsis (Araneae: Lycosidae). Molecular Phylogenetics and Evolution, 28, 576-587.

Waters, J.M., Craw, D., Youngson, J.H. \& Wallis, G.P. (2001) Genes meet geology: fish phylogeographic pattern reflects ancient, rather than modern, drainage connections. Evolution, 55, 1844-1851. 